\title{
Contrails of Small and Very Large Optical Depth
}

\author{
DAVID ATLAS \\ NASA Goddard Space Flight Center, Silver Spring, Maryland \\ ZHIEN WANG \\ Department of Atmospheric Sciences, University of Wyoming, Laramie, Wyoming
}

(Manuscript received 8 December 2009, in final form 27 April 2010)

\begin{abstract}
This work deals with two kinds of contrails. The first comprises a large number of optically thin contrails near the tropopause. They are mapped geographically using a lidar to obtain their height and a camera to obtain azimuth and elevation. These high-resolution maps provide the local contrail geometry and the amount of optically clear atmosphere. The second kind is a single trail of unprecedentedly large optical thickness that occurs at a lower height. The latter was observed fortuitously when an aircraft moving along the wind direction passed over the lidar, thus providing measurements for more than $3 \mathrm{~h}$ and an equivalent distance of $620 \mathrm{~km}$. It was also observed by Geostationary Operational Environmental Satellite (GOES) sensors. The lidar measured an optical depth of 2.3. The corresponding extinction coefficient of $0.023 \mathrm{~km}^{-1}$ and ice water content of $0.063 \mathrm{~g} \mathrm{~m}^{-3}$ are close to the maximum values found for midlatitude cirrus. The associated large radar reflectivity compares to that measured by ultrasensitive radar, thus providing support for the reality of the large optical depth.
\end{abstract}

\section{Introduction}

We have had a longstanding interest in the nature and origin of contrails both from the point of view of the cloud physics and from the continuing concern about their influence on climate. On the morning of 5 December 2008, the lead author observed a plethora of contrails to the west of his home in Silver Spring, Maryland. He photographed these throughout much of the day and obtained corresponding data by lidar and satellite observations online from the National Aeronautics and Space Administration (NASA) and National Oceanic and Atmospheric Administration (NOAA) databases.

Our goals are to understand their morphology and physical and radiative properties through the examination of the characteristics of two extremely different kinds of contrails. This paper expands upon that of Atlas et al. (2006, hereafter AWD). A concise but informative review of contrails is that of Minnis (2003). A comprehensive study of the optical depth of contrails is that of Duda et al. (2004).

Corresponding author address: David Atlas, 3116 Gracefield Road, \#322, Silver Spring, MD 20904.

E-mail: davnlu@comcast.net

\section{Photographic observations}

Photographs were taken to the southwest and east of the Atlas residence between 1451 and 1530 UTC (Times are rounded to the nearest minute; all times are in UTC.). Each of these showed between four and seven contrails, not necessarily different from those on other photographs. The photo shown in Fig. 1a was taken at 1516 UTC while looking toward the southwest. It includes a portion of the building and a tree that we have used as elevation and azimuth markers. Since we also know the heights of the contrails from the lidar record (Fig. 2), we may determine the horizontal distance $Y$ from the zenith point above the camera to any point on the frame along the $y$ axis (righthand scale), $Y=H / \tan \theta$, where $H$ is the height of the top of the contrail and $\theta$ is the elevation angle, as shown on the left-hand axis.

We see two thin sharp contrails at the center of Fig. 1a. Although the trails converge with distance from the observer, this is due mostly to perspective. The diffuse large cloud elements between them are the remnants of an older contrail that originated farther to the west and arrived simultaneously with the younger ones as shown in AWD. The photo in Fig. 1b was taken looking east at 1519 UTC. The two major contrails shown here are likely 

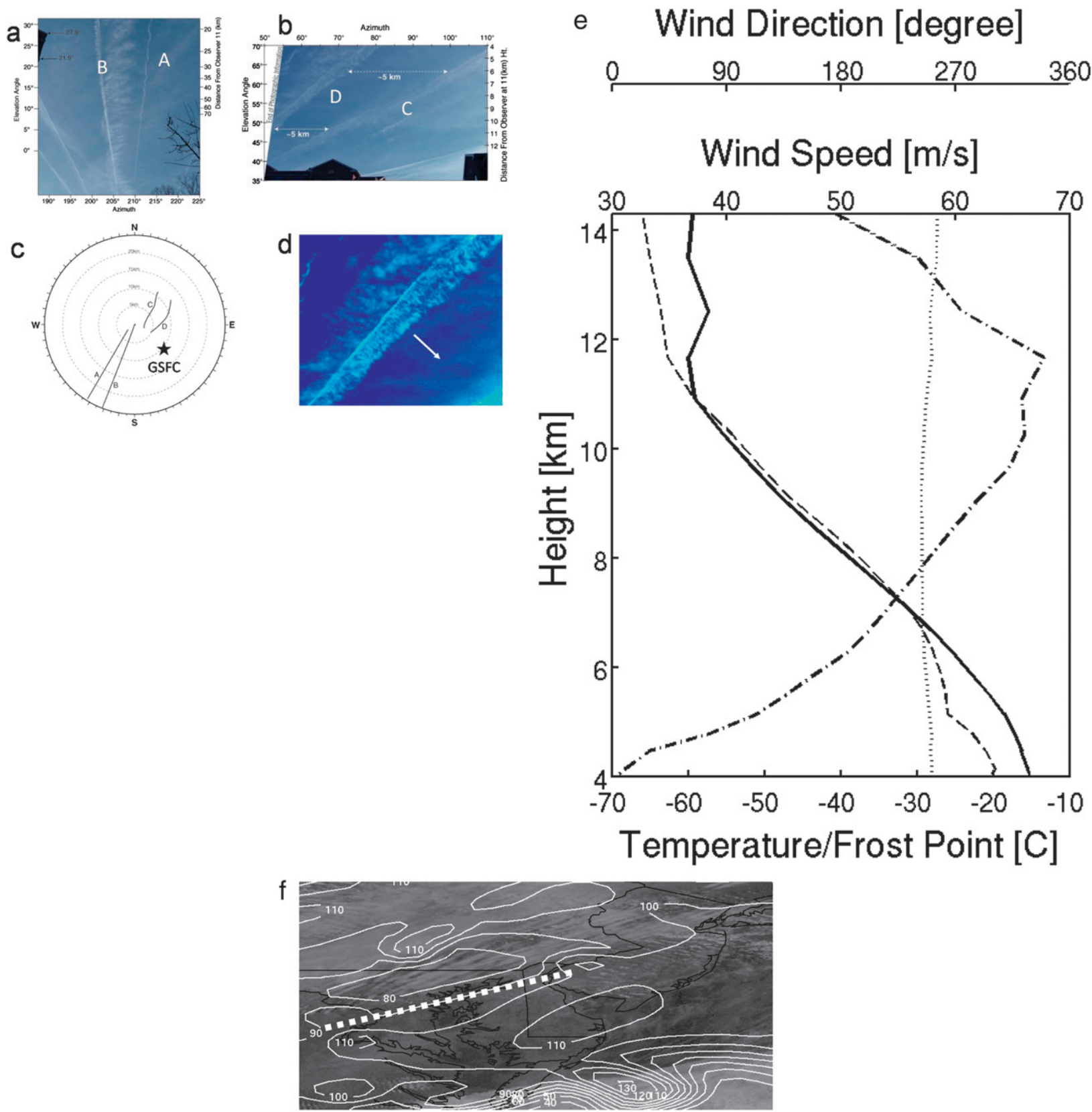

FIG. 1. (a),(b) Photos taken looking southwest at 1516 UTC and east at 1519 UTC, respectively, from the Atlas residence. Scale on right corresponds to the distance from the zenith point over the observer at the 11-km level. (c) Plan position plot of contrails shown in (a) and (b). Range circles are centered on the Atlas residence. Note position of the lidar at GSFC. Letters A, B, C, and D correspond to contrails in (a)-(c). (d) Enlarged segment of the photograph in (b) to illustrate the vertical fall streaks and their "blobby" nature. Arrow is pointing at nadir. (e) Temperature (solid line), frost point temperature (dashed line), and wind speed (dashed-dotted line) and direction (dotted line) in proximity to the Atlas residence from RUC analysis at 2000 UTC 5 Dec 2008 . At $11 \mathrm{~km}$ winds are from $250^{\circ}$ at $66 \mathrm{~m} \mathrm{~s}^{-1}$; at $7.7 \mathrm{~km}$ winds are from $240^{\circ}$ at $57 \mathrm{~m} \mathrm{~s}^{-1}$. (f) Map of maximum RHi between 500 and $300 \mathrm{hPa}$ at 2000 UTC. The dotted line represents the contrail position as seen in Fig. 3. See text for details.

to be the same as those observed to the southwest in Fig. 1a. The alphabetical letters in both photographs correspond to those in the map of Fig. 1c.

Using the ranges and azimuths in Figs. 1a and $1 \mathrm{~b}$ we have plotted the contrails on a plan position diagram in
Fig. 1c. There we see that trails A and B extend to the south-southwest while C and D extend to the northnortheast. In the 3-min interval between photos 1 and 2 , $\mathrm{C}$ and $\mathrm{D}$ have moved farther east. It is evident that $\mathrm{C}$ and $\mathrm{D}$ are the more northerly portions of $\mathrm{A}$ and $\mathrm{B}$ that have 
been slightly displaced to the east by the strong winds. Trails C and D show evidence of fall streaks of ice crystals that were not evident in A and B because we are viewing them along the direction of their fall in Fig. 1a and normal thereto in Fig. 1b. A plan view such as that in Fig. 1c, which is based on the high-resolution observations by the camera rather than the poor resolution of the lidar (see section 4), is particularly important in radiation measurements because it shows the actual portion of the sky that is optically clear.

In Fig. 1b note the streaks emanating from the contrail at the upper left. We have enlarged a segment of this contrail in Fig. 1d to illustrate its structure. These fall streaks appear aligned like the teeth of a comb, but they are of bloblike texture, suggestive of turbulence. The texture is quite different from the smooth finescale structure seen in the fall streaks shown by AWD (their Fig. 1). In view of the dry environment, the stability of the sounding, and the lack of wind shear near the tropopause, we suggest that the texture of the fall streaks may be due to evaporative cooling and turbulence induced by the descending chilled air.

\section{Meteorological observations}

Soundings of temperature and wind are shown in Fig. 1e for the location of the Atlas residence $\left(39.056^{\circ} \mathrm{N}\right.$, $76.867^{\circ} \mathrm{W}$ ). These profiles were obtained from the Rapid Update Cycle (RUC) analyses (http://ruc.noaa.gov/ppt pres/RUC20-tpb.pdf). The winds aloft exceed $55 \mathrm{~m} \mathrm{~s}^{-1}$ above $8 \mathrm{~km}$ but are remarkably constant in direction between $240^{\circ}$ and $250^{\circ}$ above $4 \mathrm{~km}$. The wind shear is modest $\left(0.005 \mathrm{~s}^{-1}\right)$ up to $10 \mathrm{~km}$ and negligible from there to $12 \mathrm{~km}$. Note that the frost point exceeds the temperature over the layer extending from 7 to $11 \mathrm{~km}$. Accordingly, any ice crystals in this layer will grow. We shall see the results of this when we discuss the lidar observations in section 4.

A map of the maximum relative humidity with respect to ice (RHi) between 500- and 300-hPa heights for 1900 UTC is shown in Fig. 1f. Although, it is well known that radiosondes underestimate the humidity at high altitudes (Miloshevich et al. 2001), the map provides a picture of the pattern of RHi. Also, the RUC model computes a grid-averaged value of relative humidity, and higher relative humidity could exist in the subgrid scale. Accordingly, a RHi $\approx 100 \%$ or less is reasonable for the occurrence of persistent contrails (Duda et al. 2004). The RHi exceeds $100 \%$ slightly only over the region running from west-southwest to east-northeast south of the Pennsylvania border. We have added a dotted line in this illustration depicting the linear contrail (shown in Fig. 3). It runs along the boundary of the region of $\mathrm{RHi}=100 \%$.
The persistence of this contrail suggests that the RHi is actually considerably greater than $100 \%$, as shown by the frost point profile in Fig. 1f.

\section{Lidar observations}

The lidar record between 1200 and 2245 UTC from the Micro-Pulse Lidar (MPL) network at the Goddard Space Flight Center (GSFC) (39.017 N, 76.867 $\mathrm{W}$; http:// mplnet.gsfc.nasa.gov/) is shown in Fig. 2. The top panel represents the Attenuated Lidar Scattering Ratio (ALSR). The middle panel represents the extinction coefficient $\left(\mathrm{km}^{-1}\right)$. The curves at the bottom show the corresponding optical depth ( $\tau$; dashed) and ice water path (IWP; $\mathrm{g} \mathrm{m}^{-2}$; solid). Layer optical depths are derived by using molecular signals above and below the cloud layer. When $\tau$ is larger than 2, the uncertainty in derived $\tau$ increases significantly because of strong solar noise and weak molecular signals above the cloud layer. Then the derived optical depths are used to constrain extinction retrievals by adjusting the lidar ratio (assuming the lidar ratio does not vary with height). During the period of 2000 to 2030 UTC, contrails almost totally attenuated MPL signals. Based on the MPL detectable signal level estimated in the nearby profiles, we put the upper limit of $\tau$ as 2.3 in this paper (with uncertainty as large as $25 \%$ ).

The period from 1230 to 1830 UTC displays echoes with tops close to the tropopause at $11 \mathrm{~km}$ and bases of $10 \mathrm{~km}$ with slight variations. We have used the $67 \mathrm{~m} \mathrm{~s}^{-1}$ winds at the 11-km level to determine the speed with which the contrails are moving. A second weak layer of echoes occurs between 8 and $9 \mathrm{~km}$ from 1615 to 2000 UTC when the echo intensity increases sharply for about $35 \mathrm{~min}$ and decays thereafter until the end of the record. From Geostationary Operational Environmental Satellite (GOES) observations, we found that the sudden increase in $\tau$ to the remarkable value of 2.3 resulted from the appearance of a single new contrail that fortuitously passed over the lidar throughout a major portion of its life cycle. Note that both layers are striated so that they are clearly not continuous clouds. Rather, the striations are due to the passage of either individual or combined adjacent contrails. This is evident in the expanded lidar record of the upper layer (not shown). There we found two to three contrail turrets in clusters of larger reflectivity separated by the striations such as those seen in Fig. 2. The close spacing between adjacent clusters in the upper layer is due to the highly compressed time scale and the 60-s averaging of the lidar signals. Such temporal averaging amounts to a distance of $4.2 \mathrm{~km}$ at the speed of the wind at the $11-\mathrm{km}$ level, and determines the effective horizontal resolution of lidar measurements at 


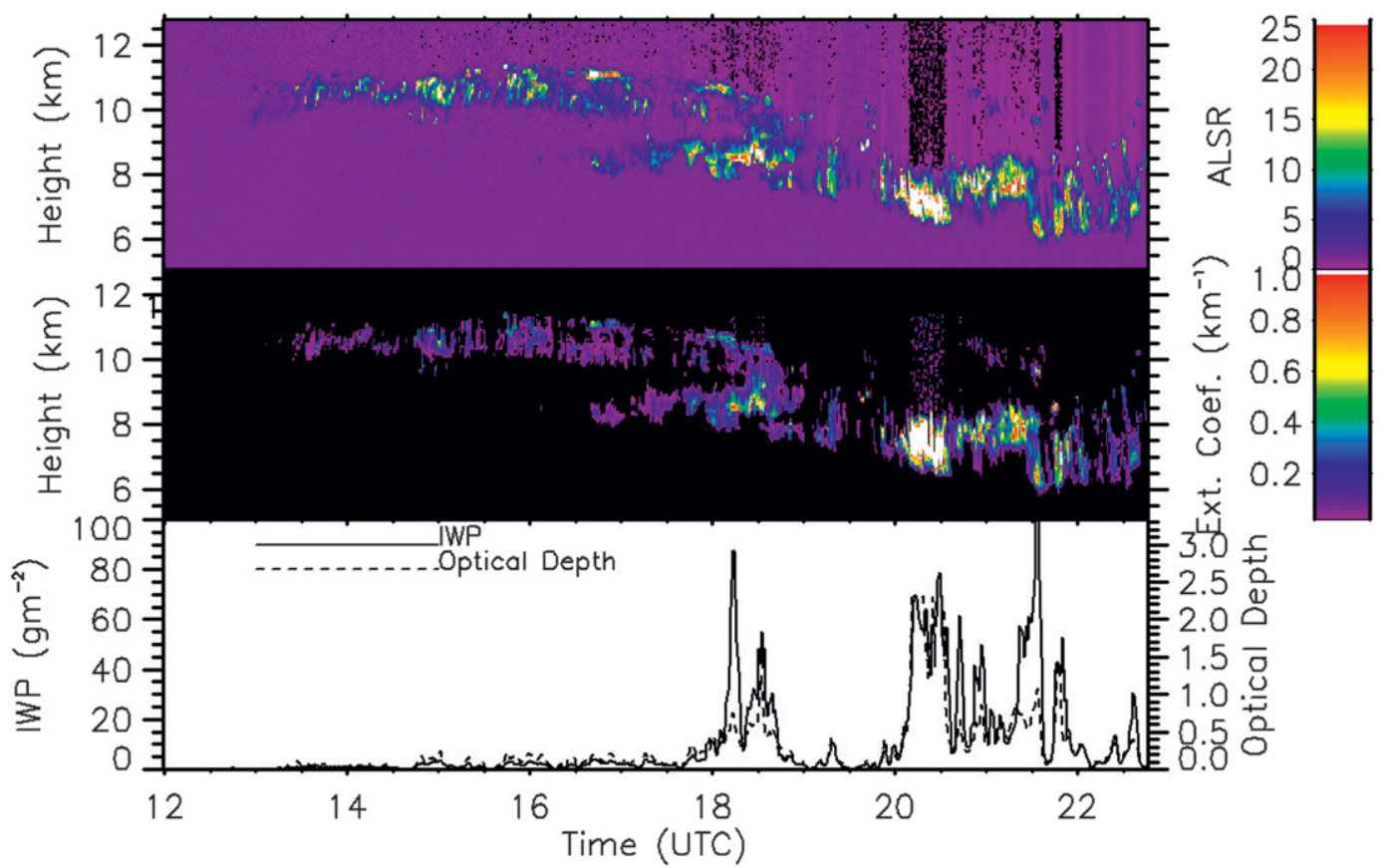

FIG. 2. MPL observations at GSFC between 1200 and 2245 UTC. (top) Attenuated Lidar Scattering Ratio (ALSR). (middle) Extinction coefficient $(\mathrm{km})^{-1}$. (bottom) Traces show the (left) ice water path (IWP, solid, $\mathrm{gm}^{-2}$ ) and (right) optical depth $\tau$.

that height. Examination of Figs. 1a and 1c shows that contrails $\mathrm{C}$ and $\mathrm{D}$ are actually spaced about $5 \mathrm{~km}$ apart. However, when viewed by the lidar at vertical incidence, they would barely be resolved from one another.

\section{Satellite observations}

Our first view from space was with the Moderate Resolution Imaging Spectroradiometer (MODIS) at 1820 UTC. This showed a large area of multiple lines oriented from northeast to southwest. However, these clouds were north of the domain covered by either the camera or the lidar and will not be discussed further. We then referred to the GOES-12 satellite visible measurements. Figure 5 shows 4 of the last of 10 GOES visible images at $\sim 15$-min intervals from 2002 to 2045 UTC. Note the line of small white elements that appears in the southwest area of the 2002 UTC image and extends toward the east-northeast in successive frames. It is a remarkable coincidence that this contrail started to pass directly over the lidar (marked by the arrow) at 2005 UTC synchronously with the strong lidar echo in Fig. 2. An earlier segment of the contrail could also be seen in the two prior images (not shown). The young contrails near the tropopause such as those in Figs. 1a and 1b are optically too thin to be detected by GOES.

The scale on Fig. 3 is shown between the images. Between the 2015 and 2045 UTC GOES images, the contrail line has advanced by $\sim 100 \mathrm{~km}$, consistent with the wind speed of $57 \mathrm{~m} \mathrm{~s}^{-1}\left(205 \mathrm{~km} \mathrm{~h}^{-1}\right)$ at the $8-\mathrm{km}$ level. Although we have no knowledge of the aircraft that produced this contrail, we assume that it has a speed $>400 \mathrm{~km} \mathrm{~h}^{-1}$ in calm air and $>600 \mathrm{~km} \mathrm{~h}^{-1}$ with this strong tailwind. Also, assuming that it requires $0.5-1 \mathrm{~h}$ for the crystals to grow to detectable size to be observed by GOES (Duda et al. 2004), the aircraft would lead the head of the detectable portion of the contrail by 100 $200 \mathrm{~km}$, respectively. Heymsfield et al. (1998) showed that relatively large precipitating ice crystals developed within 15-45 min. Also, Jensen et al. (1998, plate 1) showed that GOES-9 first detected the aircraft contrail at $\sim 30 \mathrm{~min}$. Of course, all persistent contrails are seen by eye directly behind the aircraft.

Figure 4 shows an expanded version of the dense contrail layer as observed by the lidar along with the record of the vertical IWP (solid) and $\tau$ (dashed) below. The record covers a period of $3.1 \mathrm{~h}$ or $620 \mathrm{~km}$ at the speed of $200 \mathrm{~km} \mathrm{~h}^{-1}$, perhaps the longest time of measurement of a single contrail ever reported. It occurred only because the aircraft passed over the lidar and flew exactly along the wind direction.

The record is comprised of three segments of distinctively different characteristics. These are due to both spatial and time dependent variations in the contrail structure. The segment from 1918 (19.3) to 2036 (20.6) UTC includes the strongest portion of the contrail with 


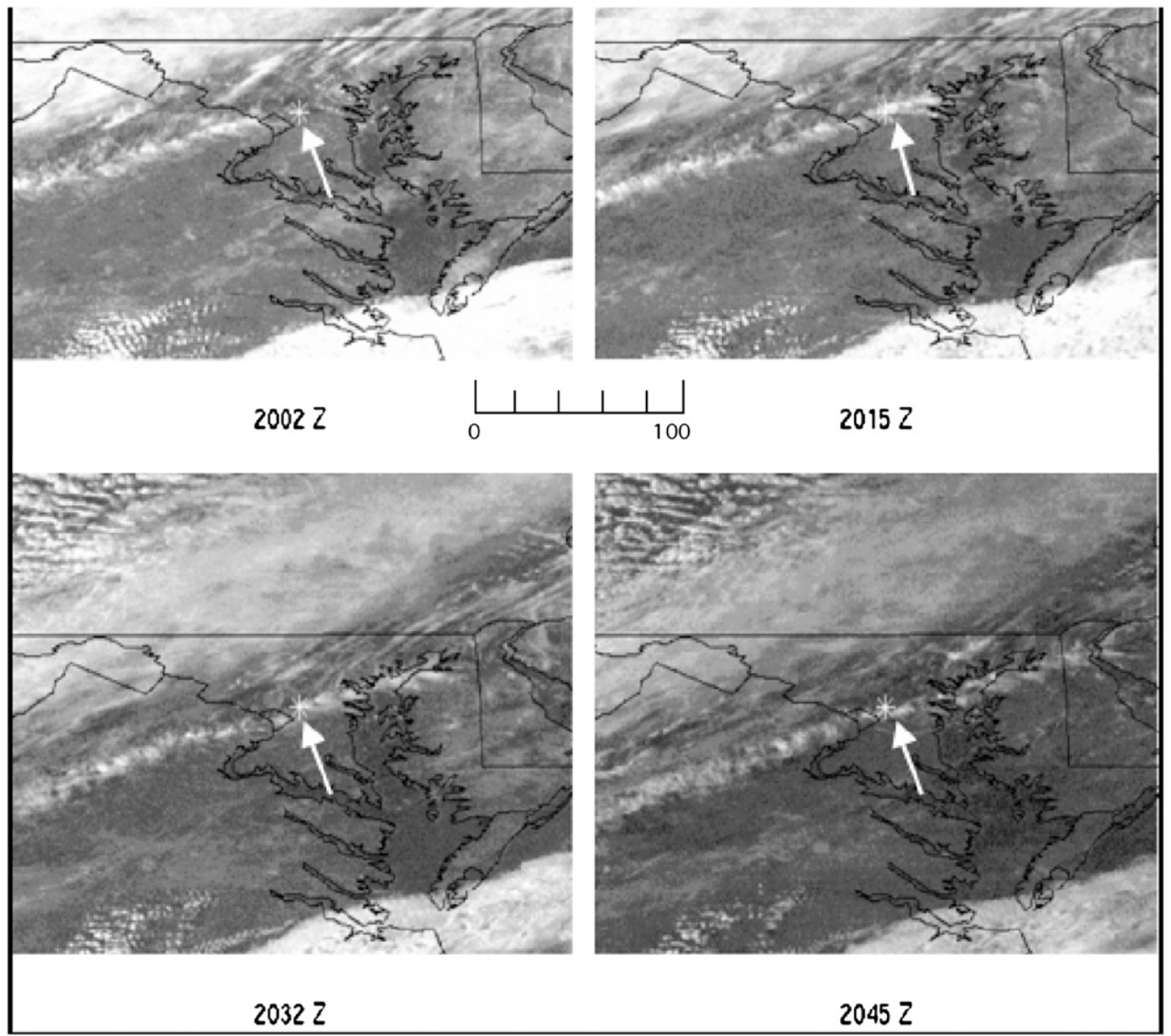

FIG. 3. Four GOES images at $\sim 15$-min intervals as marked. Notice the series of contrail elements starting in the center left of the 2002 UTC image and advancing toward the east-northeast in sequential pictures. The head of the arrow is the position of the lidar at GSFC.

maximum optical depth of 2.3 and IWP $=0.063 \mathrm{~kg} \mathrm{~m}^{-2}$. Note that the top and bottom of the zone of maximum reflectivity slope down with time, but the depth of the layer is close to $1 \mathrm{~km}$. Since $\tau$ is the average extinction coefficient $\langle\alpha\rangle$ over depth $L$, and $L=1 \mathrm{~km},\langle\alpha\rangle=2.3 \mathrm{~km}^{-1}$. Similarly, IWP $=\langle W\rangle L$, and the average ice water content $\langle W\rangle=0.063 \mathrm{~g} \mathrm{~m}^{-3}$. These large values are evidently due to the growth of large ice crystals and occur in a region of high RHi, as shown by the temperature and frost point profiles in Fig. 1e.

The segment from 20.60 to 21.40 UTC is distinctly weaker and more erratic than the first one with average optical depth of about 0.4 . It is likely that this portion of the contrail occurred in a region of lesser relative humidity than the prior one. The final segment has the smallest optical depth and is characterized by widely separated fall streaks of about 2-km depth.

The bottom panel of Fig. 4 provides an expanded version of the 19.3-20.6 UTC segment in the top panel of
Fig. 4. We see that it is actually composed of several cells each of which begins with a thin turret and ends with a low base. Note also that both top and bottom of each cell lowers with time and space. The cells between 20.3 and 20.6 UTC are clustered together and can be seen as separate cells only by the variation in the internal structure. We suggest that these cells are in fact individual fall streaks that are not separated from one another because of the 60-s time integration and their rapid motion across the lidar beam at the speed of the wind. Had they been separated they would resemble the fall streaks observed by AWD and modeled by Jensen et al. (1998). Examination of the major contrail in Fig. 3 shows that it too is composed of individual cells. Each of these is thought to be a generating cell that gives rise to a fall streak. The intense fall streaks during 20.1 and 20.5 UTC have grown in a humidity-rich environment to produce the maximum optical depths and ice water paths. 

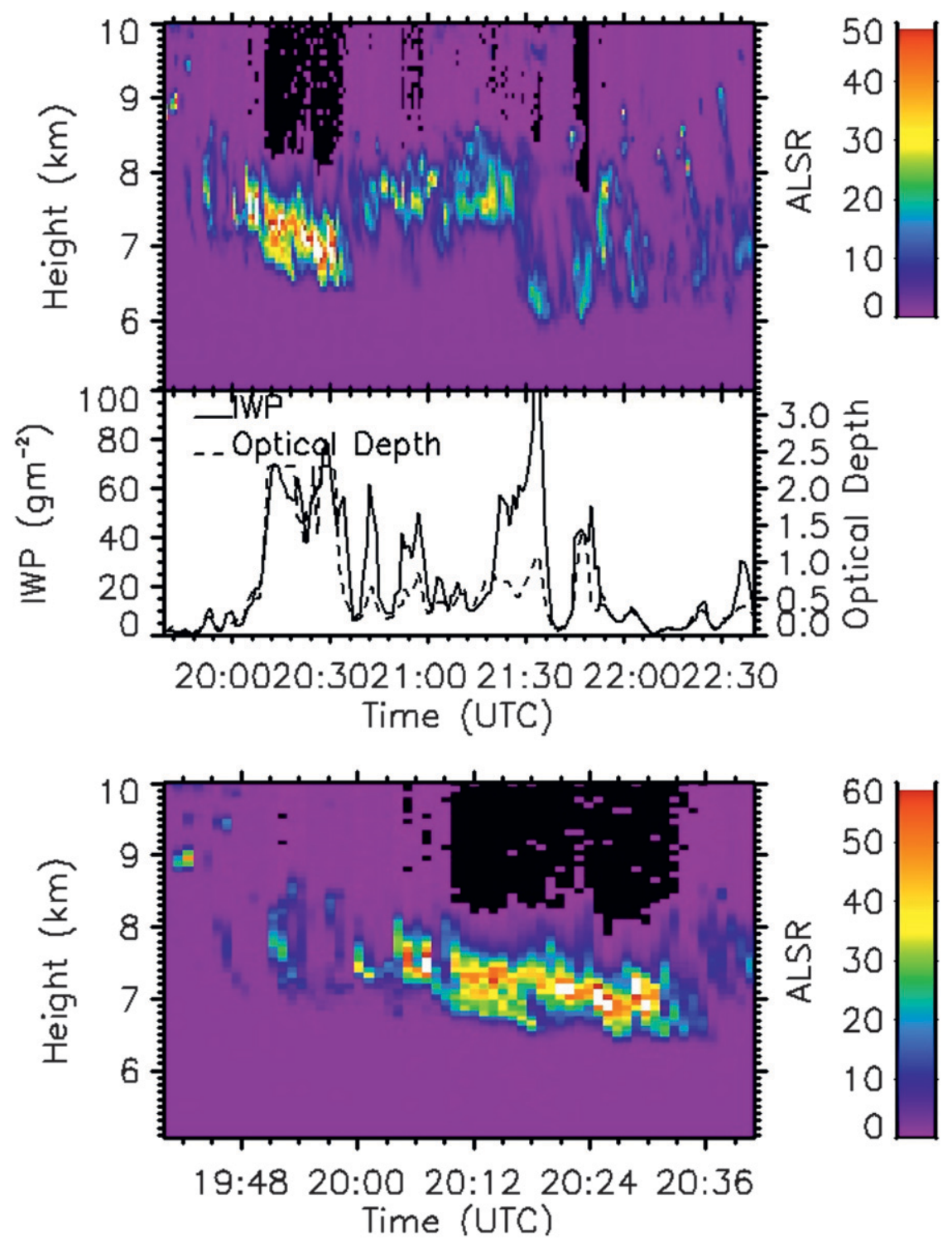

FIG. 4. (top) Expanded lidar record showing detailed structure of the contrail. Record extends over $3.1 \mathrm{~h}$ and $620 \mathrm{~km}$ of distance. (bottom) As at top, but expanded to show contrail structure from 1940 to 2040 UTC.

\section{Comparison to prior observations}

To establish the basis for comparison of the present values of $\alpha$ and $W$ to prior observations, we summarize the work of Atlas et al. (1995), who developed an ice particle parameter diagram starting with the relations

$$
\begin{aligned}
Z_{e} & =0.91 \times 10^{-6} \rho W\left(D_{o}\right)^{3}, \\
\alpha & =(3.5 / \rho)\left(W / D_{o}\right),
\end{aligned}
$$

where $Z_{e}$ is the equivalent radar reflectivity factor $\left(\mathrm{mm}^{6} \mathrm{~m}^{-3}\right), W$ is ice water content $\left(\mathrm{g} \mathrm{m}^{-3}\right), D_{o}$ is the median volume diameter, $\alpha$ is the extinction coefficient $\left(\mathrm{km}^{-1}\right)$, and $\rho$ is the ice particle density. The diagram is based on the following assumptions: 1) the particles are larger than the optical wavelength, and 2) the size distribution is a gamma function with shape factor or dispersion $\mu=1$, so that 3 ) the ratio $D_{o} / D_{e}=1.17$, where $D_{e}$ is the effective diameter.

While it is valid to use $\rho=0.91 \mathrm{~g} \mathrm{~cm}^{-3}$ for particles smaller than $100 \mu \mathrm{m}$, it is necessary to determine the dependence of $\rho$ on $D_{o}$ for larger particles. Atlas et al. (1995) used the particle size distributions of the First International Satellite Cloud Climatology Project (ISCCP) Regional Experiment (FIRE) to obtain the scattergram 
shown in Fig. 5. There we see a sequence of regression relationships $W=C Z^{b}$, where the coefficient $C$ increases with $D_{o}$ while $b$ varies from 0.930 to 1.10 as $D_{o}$ increases from 100 to $900 \mu \mathrm{m}$, respectively. Since $b$ varies only slightly they set $\langle b\rangle=0.95$. In this manner they found that the variation of $C$ corresponds very closely to that of the ice density relation found by Brown and Francis (1995):

$$
\rho=140\left(D_{o}\right)^{-1.1}\left(D_{o}>100 \mu \mathrm{m}\right) .
$$

This is close to the relation found by Heymsfield et al. (2004).

$$
\begin{aligned}
& \text { Using Eq. (3) in Eq. (1), } \\
& \qquad Z_{e}=1.27 \times 10^{-4} W\left(D_{o}\right)^{1.9} .
\end{aligned}
$$

Thus, Eqs. (2) and (4) permit the construction of the ice particle parameter diagram of $\log W$ versus $10 \log Z$ for isopleths of $D_{o}$ and $\alpha$ in Fig. 6. The diagram is valid for $D_{o}>100 \mu \mathrm{m}$ and the conditions specified above. The domain of points corresponds to midlatitude cirrus clouds. We believe that they also represent contrails except during their early stages after release from the aircraft. Note that the maximum value of $W \approx 0.1 \mathrm{~g} \mathrm{~m}^{-3}$ regardless of particle size.

There is a paucity of data of actual particle sizes in contrails. Heymsfield et al. (1998) reported maximum sizes of $250 \mu \mathrm{m}$ in a penetration of one contrail, but this depends on the age and rate of growth. AWD found particle sizes up to $1000 \mu \mathrm{m}$ in fall streaks emanating from contrails. Other measurements of sizes up to $0.5 \mathrm{~cm}$ were reported in cirrus clouds by Heymsfield (2003).

The values of $\alpha=2.3 \mathrm{~km}^{-1}$ and $W=0.063 \mathrm{~g} \mathrm{~m}^{-3}$ for the dense contrail are at the tip of the arrow in Fig. 6 . Based on the cirrus data in Fig. 6, the present values of $\alpha$ and $W$ are unlikely to exceed $4 \mathrm{~km}^{-1}$ and $0.1 \mathrm{~g} \mathrm{~m}^{-3}$, respectively. The dashed line is the regression relation found by Heymsfield et al. (2003) for midlatitude cirrus. The parameters for the mature contrail in the present study fall close to this line. The dotted line is the relationship $W \approx 0.12 Z^{0.64}$ of Matrosov et al. (2003), based on the use of a $35-\mathrm{GHz}$ radar method. Of course thick cirrus clouds may have larger optical depths, but their ice water contents are unlikely to exceed $W=0.1 \mathrm{~g} \mathrm{~m}^{-3}$.

The present value of $\tau$ is a factor 6.5 larger than that reported in the contrail case study by AWD. It is also considerably larger than all those reported in the literature (see AWD, p. 15). Moreover, both $\tau$ and $W$ also exceed the largest values observed by Wang and Sassen (2002) for cirrus as observed by the millimeter cloud radar in Oklahoma. Duda et al. (2004) report a range of $0.1<\tau<0.6$ derived by a variety of satellite methods

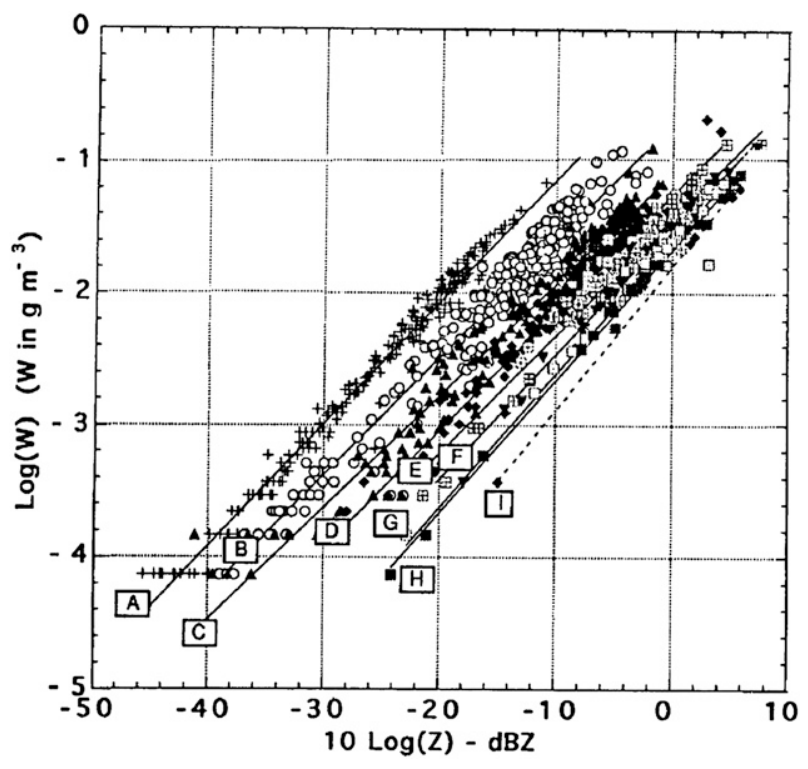

FIG. 5. Scattergram of ice water content $W$ vs radar reflectivity factor $Z$ for each of a set of values of median volume drop size, $D_{o}$. Curves A-I represent $D_{o}$ from 100 to $900 \mu \mathrm{m}$, respectively. Data are from FIRE I. From Atlas et al. (1995).

including GOES visible and infrared. D. Duda (2009, personal communication) noted the occurrence of $\tau=1$ and occasionally larger. However, these were discarded because they appeared to be untrustworthy.

At the limit of $W=0.1 \mathrm{~g} \mathrm{~m}^{-3}$ the $Z$ of cirrus clouds and beam-filling contrails have radar reflectivity in the range of $-11<Z<+7 \mathrm{~dB} Z$. As far as can be determined, only once before have contrails of any intensity been detected by radar. This was done with the ultrasensitive 3- and 10-cm radars at Wallops Island by Konrad and Howard (1974). They reported radar reflectivity in the range $-14<Z<+16.5 \mathrm{~dB} Z$. The latter observation provides some degree of confidence that the large contrail optical depth reported here is not unreasonable. In addition, Konrad and Howard were able to determine the three-dimensional structure of the contrails.

We note that the minimum detectable reflectivity of the 10.7-cm wavelength Weather Surveillance Radar1988 Doppler (WSR-88D) is $-7.5 \mathrm{dBZ}$ at a range of $50 \mathrm{~km}$ and $-13.5 \mathrm{dBZ}$ at $25 \mathrm{~km}$. In other words the U.S. network of WSR-88 radars should provide excellent opportunities to detect optically dense contrails at modest ranges. Recent developments in radar signal processing at the National Severe Storms Laboratory have increased the sensitivity by $7 \mathrm{~dB}$ (V. Melnikov 2009, personal communication), thus indicating even greater promise for such studies. Such sensitive scanning radars promise to provide further insight into the nature and frequency of the stronger contrails. 


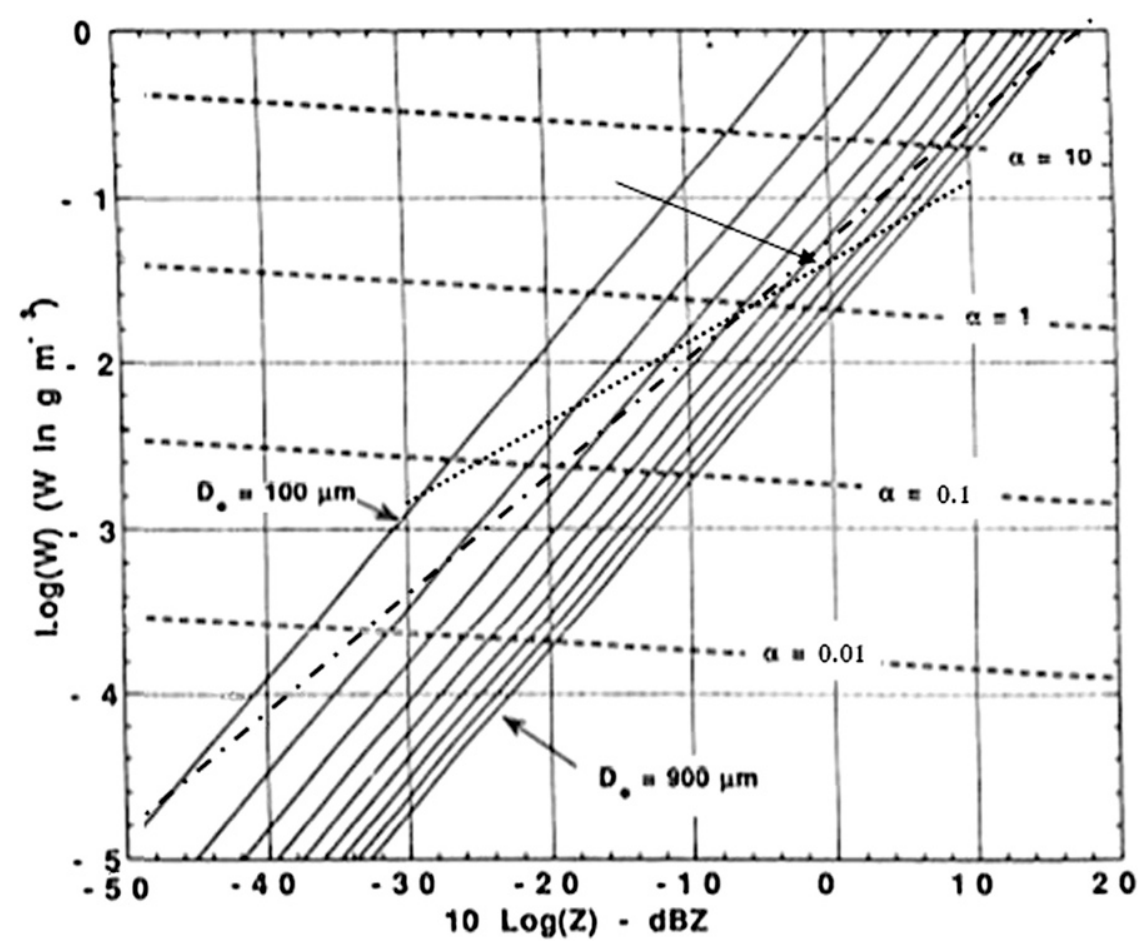

FIG. 6. Ice particle parameter diagram for cirrus clouds and contrails. Tip of solid arrow corresponds to $\alpha=2.0 \mathrm{~km}^{-1}$ and $W=0.06 \mathrm{~g} \mathrm{~m}^{-3}$. Dotted-dashed: Heymsfield et al. 2003; dotted curve: Matrosov et al. 2003. See text for details.

\section{Summary and conclusions}

In this work we have studied both young contrails of very small optical depth and an older one of very large optical depth on the same day. Our tools were a simple digital camera, a vertically pointing lidar, and the GOES satellite. The young thin contrails with average optical depth of 0.2 were observed near the tropopause and moved very rapidly toward the east-northeast with a speed of $200 \mathrm{~km} \mathrm{~h}^{-1}$. These trails emanated from aircraft flying toward the south-southwest and passed over the lidar very frequently because of the high wind speed. The blobby nature of the fall streaks from these trails is suggestive of turbulence. The combination of height measured by the lidar and the camera images provide a high-resolution plan position display of the trails showing the optically clear zones.

We also observed a contrail of very large optical depth that passed directly over the lidar fortuitously, thus permitting measurements of optical depth and ice water path for about $3 \mathrm{~h}$. The leading edge of this trail advanced with the wind at $\sim 200 \mathrm{~km} \mathrm{~h}^{-1}$ toward the east-northeast. The trail would have been immediately visible to the eye but not to GOES until $\sim 0.5-1 \mathrm{~h}$ later, the particles having grown to produce sufficient albedo in the interim. Maximum optical depth occurred $\sim 2.5 \mathrm{~h}$ after initial detection by the lidar to produce $\tau=2.3$ and IWP $=63 \mathrm{~g} \mathrm{~m}^{-2}$. With layer thickness of $1 \mathrm{~km}$ shown by the lidar, these values correspond to extinction coefficient $\alpha=2.3 \mathrm{~km}^{-1}$ and ice water content $W=0.063 \mathrm{~g} \mathrm{~m}^{-3}$. The latter values are near the upper limit of $\alpha=4 \mathrm{~km}^{-1}$ and $W=0.1 \mathrm{~g} \mathrm{~m}^{-3}$ for midlatitude cirrus clouds. The structure of the contrail as seen by the lidar varies both spatially and temporally in large part because of the variations in relative humidity with respect to ice. The large values of ice water content, optical depth, radar reflectivity, and lifetime are due to the growth of the crystals in the layer of large RHi.

The probability of occurrence of an observing opportunity such as the present one is exceedingly small. Not only does the aircraft have to pass over the lidar, but it must fly along the wind direction in a region of large relative humidity relative to ice. Sensitive scanning radars such as the WSR-88D may detect dense contrails at modest ranges; they offer new opportunities for further study and validation.

Acknowledgments. We are pleased to acknowledge Larry Oolman of the University of Wyoming and John Jones of GSFC for technical assistance, Gala Wind of GSFC and Prof. Michael King of the University of Colorado, Dr. Dennis Chesters of GSFC for the GOES observations, and Ellsworth (Judd) Welton and his team 
at GSFC for effective access to the MPLNET lidar data. The lead author is especially grateful to Drs. Franco Einaudi and William Lau of GSFC for their hospitality over a period exceeding 25 years. Prof. Wang's efforts were supported in part by NSF under award of Grant ATM 0645644.

\section{REFERENCES}

Atlas, D., S. Y. Matrosov, A. J. Heymsfield, M.-D. Chou, and D. B. Wolff, 1995: Radar and radiation properties of ice clouds. J. Appl. Meteor., 34, 2329-2344.

_ - Z. Wang, and D. P. Duda, 2006: Contrails to cirrusMorphology, microphysics, and radiative properties. J. Appl. Meteor. Climatol., 45, 5-19.

Brown, P. R. A., and P. N. Francis, 1995: Improved measurements of the ice water content in cirrus using a total-water probe. J. Atmos. Oceanic Technol., 12, 410-414.

Duda, D. P., P. Minnis, L. Nguyen, and R. Palikonda, 2004: A case study of the development of contrail clusters over the Great Lakes. J. Atmos. Sci., 61, 1132-1146.

Heymsfield, A. J., 2003: Properties of tropical and midlatitude ice cloud particle ensembles: Part I: Median mass diameters and terminal velocities. J. Atmos. Sci., 60, 2573-2591.

— R. P. Lawson, and G. E. Sachse, 1998: Growth of ice crystals in a precipitating contrail. Geophys. Res. Lett., 25, 1335-1338.
- A. Bansemer, C. Schmitt, C. Twohy, and M. P. Poellot, 2004: Effective ice particle densities derived from aircraft data. J. Atmos. Sci., 61, 982-1003.

- S. Matrosov, and B. Baum, 2003: Ice water path-optical depth relationships for cirrus and deep stratiform ice cloud layers. J. Appl. Meteor., 42, 1369-1390.

Jensen, E. J., A. I. Ackerman, D. E. Stevens, O. B. Toon, and P. Minnis, 1998: Spreading and growth of contrails in a sheared environment. J. Geophys. Res., 103, 31 557-31 567.

Konrad, T. G., and J. C. Howard, 1974: Multiple contrail streamers observed by radar. J. Appl. Meteor., 13, 563-572.

Matrosov, S. Y., M. D. Shupe, A. J. Heymsfield, and P. Zuidema, 2003: Ice cloud optical thickness and extinction coefficient estimates from radar measurements. J. Appl. Meteor., 42, 1584 1597.

Miloshevich, L. M., H. Vömel, A. Paukunen, A. J. Heymsfield, and S. J. Oltmans, 2001: Characterization and correction of relative humidity measurements from Vaisala RS80-A radiosondes at cold temperatures. J. Atmos. Oceanic Technol., 18, $135-156$.

Minnis, P., 2003: Contrails. Encyclopedia of Atmospheric Sciences, J. Holton, J. Pyle, and J. Curry, Eds., Academic Press, $509-520$.

Wang, Z., and K. Sassen, 2002: Cirrus cloud microphysical property retrieval using lidar and radar measurements. Part I. Algorithm description and comparison with in situ data. J. Appl. Meteor., 41, 218-229. 